\title{
Genetic Algorithms in Antennas and Smart Antennas Design Overview: Two Novel Antenna Systems for Triband GNSS Applications and a Circular Switched Parasitic Array for WiMax Applications Developments with the Use of Genetic Algorithms
}

\author{
Stylianos C. Panagiotou, ${ }^{1}$ Stelios C. A. Thomopoulos, ${ }^{1}$ and Christos N. Capsalis ${ }^{2}$ \\ ${ }^{1}$ Institute of Informatics and Telecommunications, National Center for Scientific Research "Demokritos", \\ Patriarchou Grigoriou and Neapoleos Street, Agia Paraskevi, 15310 Attiki, Greece \\ ${ }^{2}$ School of Electrical and Computer Engineering, National Technical University of Athens, 9 Iroon Polytechniou Street, \\ Zografou, 15773 Attiki, Greece
}

Correspondence should be addressed to Stylianos C. Panagiotou; stelios.panagiotou@iit.demokritos.gr

Received 1 August 2014; Accepted 1 September 2014; Published 11 December 2014

Academic Editor: Jaume Anguera

Copyright @ 2014 Stylianos C. Panagiotou et al. This is an open access article distributed under the Creative Commons Attribution License, which permits unrestricted use, distribution, and reproduction in any medium, provided the original work is properly cited.

Genetic algorithms belong to a stochastic class of evolutionary techniques, whose robustness and global search of the solutions space have made them extremely popular among researchers. They have been successfully applied to electromagnetic optimization, including antenna design as well as smart antennas design. In this paper, extensive reference to literature related antenna design efforts employing genetic algorithms is taking place and subsequently, three novel antenna systems are designed in order to provide realistic implementations of a genetic algorithm. Two novel antenna systems are presented to cover the new GPS/Galileo band, namely, L5 (1176 MHz), together with the L1 GPS/Galileo and L2 GPS bands (1575 and $1227 \mathrm{MHz}$ ). The first system is a modified PIFA and the second one is a helical antenna above a ground plane. Both systems exhibit enhanced performance characteristics, such as sufficient front gain, input impedance matching, and increased front-to-back ratio. The last antenna system is a five-element switched parasitic array with a directional beam with sufficient beamwidth to a predetermined direction and an adequate impedance bandwidth which can be used as receiver for WiMax signals.

\section{Introduction}

The basic principles of genetic algorithms (GAs) and their applications in computer systems were presented by Holland [1] and de Jong [2] in 1975 and described in detail by Goldberg [3]. The GA starts forming, usually by random manner, an initial population of chromosomes (individuals). The performance of each individual is evaluated by the objective function or the fitness function, which determines the goal in each optimization problem. A high value on the objective function implies a good chromosome. After the initial chromosomes are created, a thoughtful selection strategy determines chromosomes which will take part in the process of evolution. More specifically, these individuals undergo transformations through stochastic, genetic operators to create offspring, according to the logic of domination of the fittest. Chromosomes are mated with each other (according different techniques) to give birth to the offspring in which there is genetic material from both parents, chromosomes. The two types of genetic operators are crossover in which new individuals are constructed by combining genetic material from preexisting ones and mutation, thus the modification of the genetic material for the synthesis of new individuals. The new set of chromosomes produced by this mating process forms the next generation chromosomes, although not impossible to save chromosomes from previous generation and to introduce the next. Then the performance of the new population individuals is calculated. In each generation the 
number of chromosomes is kept constant. This process is repeated for several generations, until a termination criterion is met [3-8].

A GA has significant advantages over traditional optimization techniques as follows [8].

(i) It can be applied in any problem.

(ii) It conducts a universal research in the solutions spaces.

(iii) It does not require prior knowledge of the optimization problem.

(iv) It does not depend on the initial conditions of the search.

(v) It optimizes continuous or discrete parameters.

(vi) It does not require derivative information on the cost function.

(vii) It works well with large number of variables.

(viii) It can be run in parallel on multiple computers.

(ix) It optimizes variables with quite complex cost surfaces.

(x) It provides a list of best parameters, not just a single solution.

(xi) It can encode parameters.

(xii) It can work with numerical data, with experimental data or analytical functions.

For these reasons, GAs have become a very popular optimization tool. Their computational modeling is applied on various problems in a wide range of disciplines, such as aerospace, operational research, social science, and quantum physics [2, 9-11]. In the field of electromagnetism, they have been applied in the design and optimization of the geometric characteristics of antennas and arrays [12-47], in EMC problems $[48,49]$, in multiobjective optimization problems of arrays, and in optimization problems using computational methods [50-58].

It is not certain that the solution ultimately provided by the GA is optimal. But in problems of electromagnetic nature and in particular issues of design and development of antennas, the following rules $[8,50]$, which are not binding, usually contribute in finding the global optimal solution, if of course this exists.

(i) The selection of appropriate coding depends on the test problem. Still, genes related to each other should be placed in adjacent positions in the chromosome. A typical example is the encoding of complex numbers, where two genes are used for the description of the amplitude and phase, respectively.

(ii) Population size is a critical factor. The number of generations determines whether they actually achieve convergence and the number of chromosomes determines how good the solution will be in the case of convergence. The larger the population is, the greater percentage of the solution space is investigated. On the other hand, this approach increases the computational cost in the performance of GA. (iii) An important parameter for the performance of GA is the crossover probability $p_{c}$ which can take values between 0.5 and 0.9. Higher values provide faster search space solutions. Values between 0.7 and 0.8 were proved effective in most problems [5].

(iv) The mutation probability $p_{m}$ is always chosen relatively small, typically 0.15 . Values greater than 0.15 enable the GA to escape from the local optima but can lead to removing individuals with excellent performance close to the global optimal one, delaying or preventing convergence [7].

(v) The use of elitism techniques is recommended.

When designing an antenna or array with the method of GAs, the output can be the synthesis of a desired radiation pattern, the minimization of the side lobes level of the radiation pattern, the composition of diagram with multiple lobes or nulls towards specific directions, and the achievement of input impedance matching at a single frequency point or frequency interval. The design parameters may include the positions of the elements of the array, their sizes, their current excitations, and so forth.

In [12] a printed dual band antenna is designed, using a GA that alters its geometrical characteristics. A method for reducing the side lobes of a planar square array is presented in [13], which is based on the use of a GA that modifies the weight coefficients in each element. In [15] a GA with a high mutation rate (30\%) to minimize electromagnetic interaction (coupling) between two VHF-UHF antennas placed on the fuselage of a military aircraft is proposed. The technique of GAs is used to determine an optimal set of excitation coefficients and an optimal placement of elements of a nonuniform circular array [16], where the aim is to extract a radiation pattern with maximum reduction of the highest side lobe level, subject to the constraint of a constant beam width. A compact genetic antenna consisting of a set of leads that are connected in series and loaded with suitable loads is designed in [27]. The shape of the antenna, the positions of the elements, and the values of the loads are optimized using a GA of real encoding. In [29] a circular switched parasitic array of log-periodic dipole antennas (LPDAs) is introduced. The overall structure is subjected to an optimization procedure in order to achieve significant directivity and operational bandwidth at the $3.1 \mathrm{GHz}-$ 10.6 GHz frequency band with the use of the GAs technique. Beam steering is performed by selecting which one LPDA is attached to the signal source. Furthermore, design methods of wideband antenna using GAs are discussed in [36], while a GA optimizes an array of vertical dipoles over ground plane in [37]. A technique that combines the Schelkunoff method with a genetic algorithm for the synthesis of linear arrays with complex feed coefficients and random radiation patterns is mentioned in [39]. GA optimization of high-directivity microstrip patch antennas and miniature microstrip patch antennas have been dealt with in $[46,47]$, respectively.

Indicatively, in [59] a multicriteria optimization problem is presented. The design of a classical Yagi-Uda antenna and the design a modified Yagi-Uda antenna with additional parasitic elements in the region of the active element, which act 
as reflectors, are featured. Miscellaneous objective functions that combine requirements for directionality, the front-toback ratio, and input impedance are examined. Any such requirement is introduced in the objective function and has its own weighting. Therefore interesting comparisons with different rates weight for various structures of classical and modified Yagi-Uda arrays with an operating frequency of $2.4 \mathrm{GHz}$ are featured, while the optimal solutions are studied in regard of the bandwidth they achieve. The work in [60] deserves special mention, which develops a tailored GA of real imaging that alters the mechanisms (crossover and mutation) dynamically during the optimization. So, convergence is accelerated and the need for redefining the parameters decreases significantly. The efficiency of the method is demonstrated through application in intelligent adaptive arrays where the height of the side lobe is determined by appropriately choosing the amplitudes and/or phases of the weights of the elements.

A lot of attention has been paid to the concept of developing smart antennas for DVB-T applications utilizing the GAs technique in a series of works by the authors [6163], where different array configurations for such applications are introduced. More specifically, [61] proposed a broadband switched-parasitic array suitable for switched-beam DVB$\mathrm{T}$ applications in the IV UHF band. A broadband, sevenelement switched-parasitic array having six available directive beam lobes was designed for the channels 51-69 of the $\mathrm{V}$ UHF band in [62], whereas a new technique for the design of broadband, circular switched-parasitic arrays for use as portable DVB-T receivers in the V UHF band was developed in [63]. In [64], the design of an optimized electronically steerable passive array radiator (ESPAR) antenna, for portable or mobile DVB-T reception, is proposed. Finally, a lowcost and profile switched-beam array, suitable for fixed and portable DVB-T applications in the V UHF band, is proposed in [65], where the array comprises eight wire elements lying on the horizontal plane and a set of four switching beam patterns is provided.

In the following sections of the paper, a modified planar inverted $\mathrm{f}$ antenna (PIFA) and a helical antenna above a ground plane are proposed for triband GNSS (GPS and Galileo) operation on the L1/L2/L5 bands. Their advantages are significant directivity, satisfactory impedance matching to the feeding line, and adequate front-to-back ratio. In order to achieve these objectives, both configurations are subjected to an optimization procedure by varying their physical dimensions.

A conventional PIFA is depicted in Figure 1. PIFA consists of a ground and a top plane, interconnected with shorting strip and a feed wire. By altering the dimensions of the top plate, the height above the ground plane, and the size of the ground plane itself, a variation of the resonant frequency and impedance bandwidth is observed. Firstly, a conventional PIFA is designed and the ultimate modified PIFA is obtained by changing the shape (inserting holes) of the top plate.

Thereafter, a helical antenna above a finite square ground plane operating in the axial mode suitable for GNSS applications is considered (Figure 2). The presence of the ground

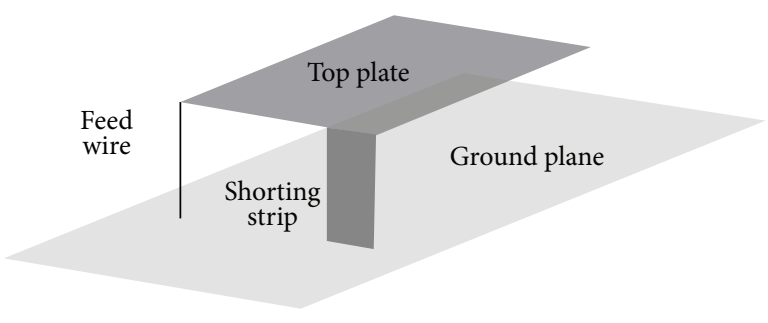

FIgURE 1: A conventional PIFA.

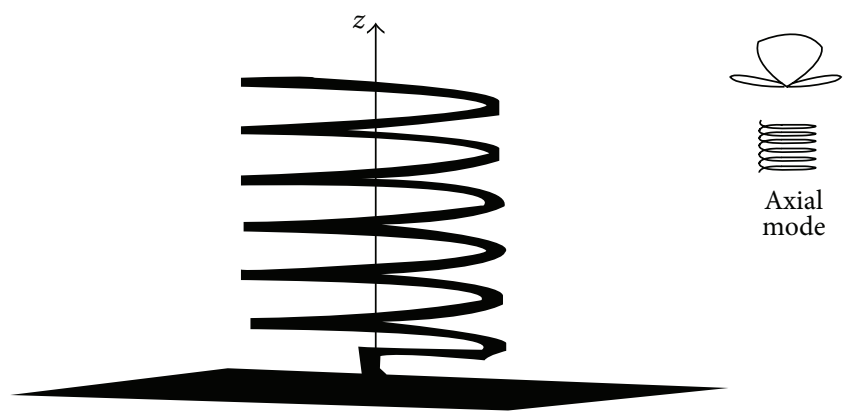

FIGURE 2: A helical antenna above ground plane operating on axial mode.

plane enhances the performance of the antenna in terms of bandwidth and directivity.

Moreover, a broadband circular switched parasitic antenna (CSPA) with two active elements, suitable for WiMAx applications, is proposed. The array under consideration consists of five elements (dipoles); one fixed parasitic element is placed at the center of the structure, while the four remaining elements form a circle surrounding it. As displayed in Figure 3, two neighboring peripheral elements are connected to identical replicas of the source signal, while all the rest parasitic elements are short-circuited. The main beam direction is steered by switching the position of the active and the parasitic elements along the circumference of the array. The objective of this design is to obtain a configuration capable of producing four directional radiation patterns, covering the whole azimuth plane with main beams oriented towards $0^{\circ}, 90^{\circ}, 180^{\circ}$, and $270^{\circ}$. Moreover, $3 \mathrm{~dB}$ beamwidths of $90^{\circ}$ and relative sidelobe levels of no more than $-6 \mathrm{~dB}$ and a sufficient input impedance matching bandwidth are required. Due to symmetry, only the radiation pattern pointing towards $0^{\circ}$ needs to be optimized. The frequency band that will be examined regards the $[3300 \mathrm{MHz}, 3800 \mathrm{MHz}]$ band allocated for WiMax applications. Optimization parameters include the length of the central element, the length of the peripheral elements, and the radius of the array.

\section{Materials and Method}

Simulation and design of the aforementioned antenna systems are made feasible with the aid of the SuperNEC software package. SuperNEC is a hybrid MoM, UTD (uniform theory of diffraction) antenna and electromagnetic simulation 


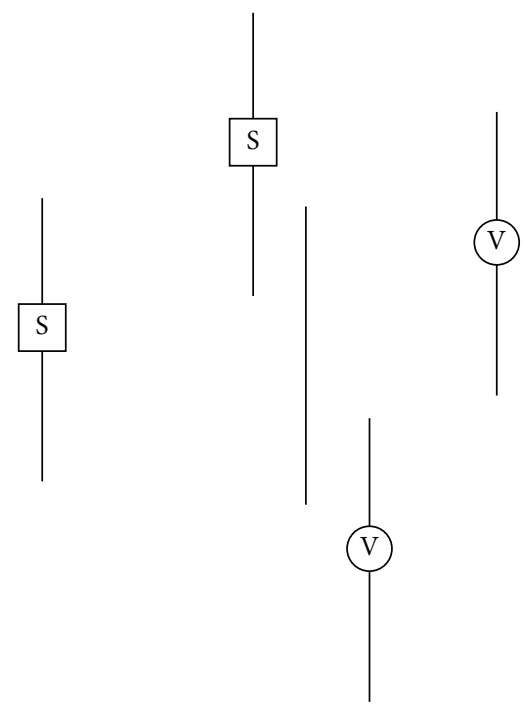

Figure 3: A 5-element CSPA.

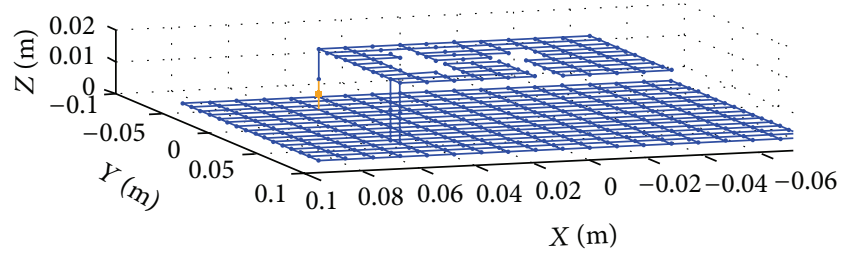

Figure 4: Implementation of the modified PIFA with SuperNEC.

program. The MoM primitives available in the code are wire segments, whereas the UTD primitives supported are dielectrically coated plates and elliptical cylinders. The MoM is a numerical electromagnetic technique used to compute the radiation pattern and input impedance of wire-structured antennas [66]. The optimization procedure per structure is performed by employing the GA module included in the package [67].

2.1. Design of the Modified PIFA. For software compatibility reasons, the ground plane, the top plate, and the shorting strip of the PIFA are modeled as wire grid plates. Moreover, the feed wire is excited by an applied field voltage source (Figure 4). The final PIFA structure is implemented in such a way that the input values of the user-defined dimensions for each component of this structure are given in terms of the number of wire segments, instead of their physical values. Taking into consideration that the segment length (seglen) is a fraction of the wavelength, $\lambda$, at $1575 \mathrm{MHz}$, the electrical size of the PIFA is kept constant. This concept ensures compatibility via the handling of the PIFA structure in the SuperNEC design procedure. Each segment length was selected to be equal to seglen $=0.05 \lambda$.

The variation of parameters that took part in the GA optimization procedure is included in Table 1 . The optimum value for the voltage standing wave ratio (VSWR) is 1 (with
TABLE 1: Input parameters and results of the GA optimization procedure for the PIFA.

\begin{tabular}{lcc}
\hline Parameter & Variation range & GA result \\
\hline Top plate length & 2 seglen-16 seglen & 10 seglen \\
Top plate width & 3 seglen-10 seglen & 9 seglen \\
Ground plate length & 2 seglen-24 seglen & 20 seglen \\
Ground plate width & 3 seglen-24 seglen & 15 seglen \\
Height & 1 seglen-4 seglen & 2 seglen \\
Shorting strip width & 1 seglen-4 seglen & 1 seglen \\
\hline
\end{tabular}

a characteristic impedance of $50 \Omega$ as reference value) and the desired gain is $9 \mathrm{dBi}$. The objective function $(\mathrm{OF})$ used to evaluate the solutions is given in (1). This function was built in SNEC, where the user is enabled to determine the required VSWR and gain values:

$$
\mathrm{OF}=\sum_{n}\left[\left(\frac{G\left(f_{n}\right)}{9}\right)^{2}+\left(\frac{1}{\operatorname{VSWR}\left(f_{n}\right)}\right)^{2}\right],
$$

where $f_{n}$ are the 3 frequency points of interest $(1575,1227$, and $1176 \mathrm{MHz})$, while $G\left(f_{n}\right)$ and $\operatorname{VSWR}\left(f_{n}\right)$ are the front gain at $\left(\varphi=0^{\circ}, \theta=0^{\circ}\right)$ and the VSWR values referring to the frequency point $f_{n}$.

The total population consists of 250 generations, with 60 chromosomes per generation. The selection method was population decimation, while adjacent fitness pairing was the mating scheme. The crossover point was chosen randomly and each chromosome was divided at a gene level. The mutation probability was equal to 0.15 .

To obtain a more suitable configuration, which will be more compliant to the design constraints, the shape of the top plate is modified by deleting segments manually. The resulting structure is therefore a modified PIFA, depicted in Figure 4, and its dimensions are approximately $17.1 \mathrm{~cm} \times$ $14.28 \mathrm{~cm} \times 2 \mathrm{~cm}$.

2.2. Design of the Helical Antenna above Ground Plane. The SNEC implementation of the helical antenna above ground plate is displayed in Figure 5. Each GA solution string of the helix geometry (representing the corresponding varying parameters) comprised possible values of the space between the helix turns, the helix length, the radius of the bottom and top turns, and the size of the square plate. The height of the helix above the conductive plane and the wire radius were kept constant and were equal to $1 \mathrm{~cm}$ and $4 \mathrm{~mm}$, respectively.

Again, the design requirements are to achieve a value of 1 and $9 \mathrm{dBi}$ for the VSWR and the front gain, respectively; thus the objective in (1) is used. The selection method is population decimation, while adjacent fitness pairing is the mating scheme. The crossover point was chosen randomly and each chromosome is divided at a gene level. The mutation probability is equal to 0.15 . The variation intervals of the GA structure parameters and the final results of the implementation of the GA algorithm are depicted in Table 2. 
TABLE 2: Input parameters and results of the GA optimization procedure for the helical antenna.

\begin{tabular}{lcc}
\hline Parameter & $\begin{array}{c}\text { Variation } \\
\text { intervals }(\mathrm{mm})\end{array}$ & Results (mm) \\
\hline Turn spacing & $5-20$ & 17 \\
Length of the helix & $60.1-99.9$ & 85.4 \\
Base radius & $20-40$ & 38 \\
Tip radius & $25-35$ & 27 \\
Length (width) of ground plane & $40-120$ & 100 \\
\hline
\end{tabular}

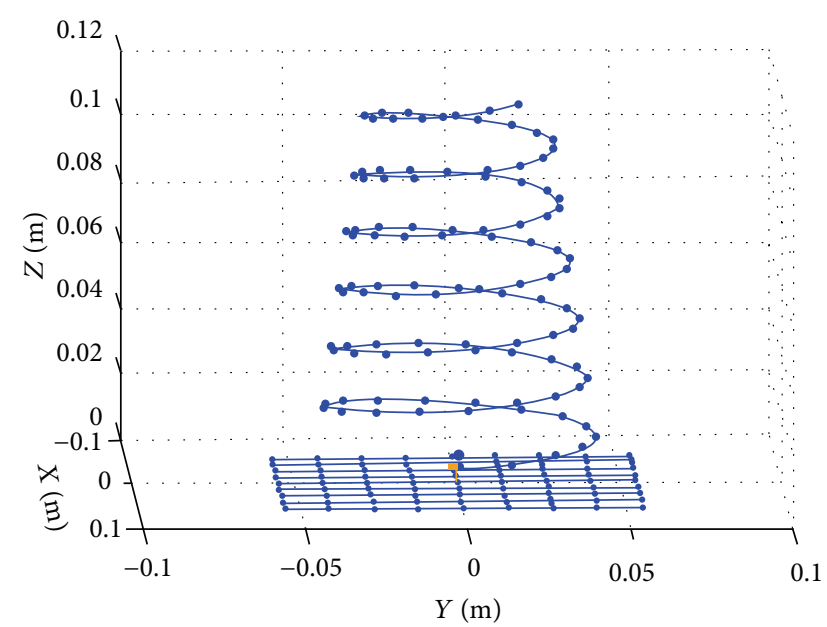

FIGURE 5: Implementation of the helical antenna above finite ground plane with SuperNEC.

2.3. Design of the Circular Switched Parasitic Array. The SNEC implementation of a 5-element CSPA antenna, with two adjacent peripheral elements active, a central parasitic element short-circuited, and the remaining peripheral parasitic elements short-circuited, above a square wire grid plate is displayed in Figure 6.

As already being pointed out, only the radiation pattern pointing towards $0^{\circ}$ needs to be optimized. The other three diagrams, which will have the same shape with the only difference that the main beams are oriented at the direction of $90^{\circ}, 180^{\circ}$, and $270^{\circ}$, respectively, are obtained when the adjacent active elements are interchanged in a rotational manner around the array, because of the symmetry that this array exhibits.

A set of 360 points is used to specify the radiation pattern. Let $G(\varphi)$ be the directivity determined with an angular step of $1^{\circ}$ and $G_{\max }$ the maximum directivity.

The objective function is formed as follows [68].

Within the main lobe, which is shaped by taking into account 89 points, the error term is

$$
e_{1}=\frac{1}{89} \sum_{\phi=-44^{\circ}}^{44^{\circ}}\left[\left(\frac{G(\phi) / G_{\max }-0.5}{0.5}\right)^{2} u\left(0.5-\frac{G(\phi)}{G_{\max }}\right)\right] \text {, }
$$

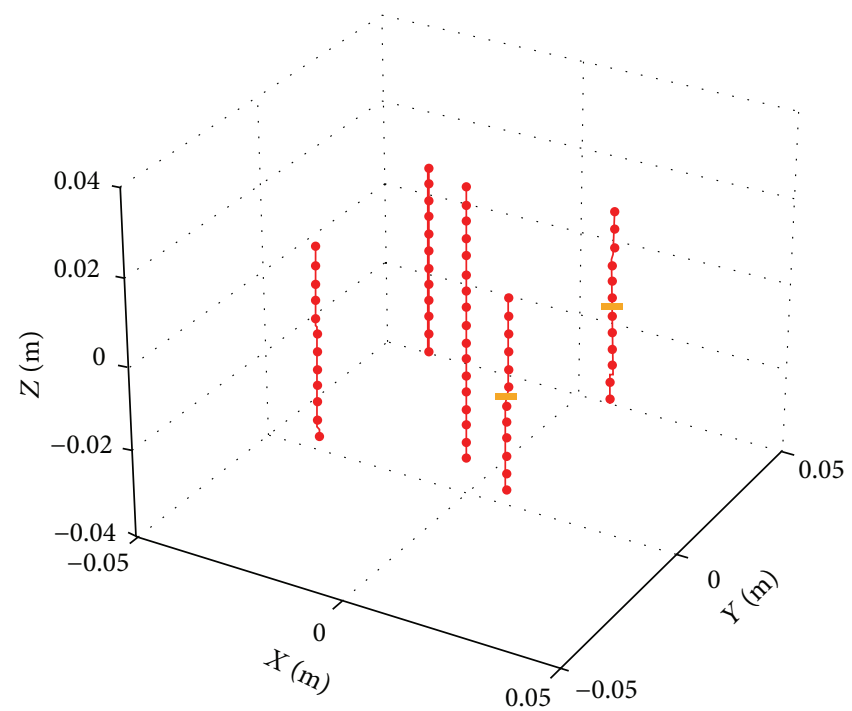

FIGURE 6: Implementation of the proposed circular switched parasitic array with SuperNEC.

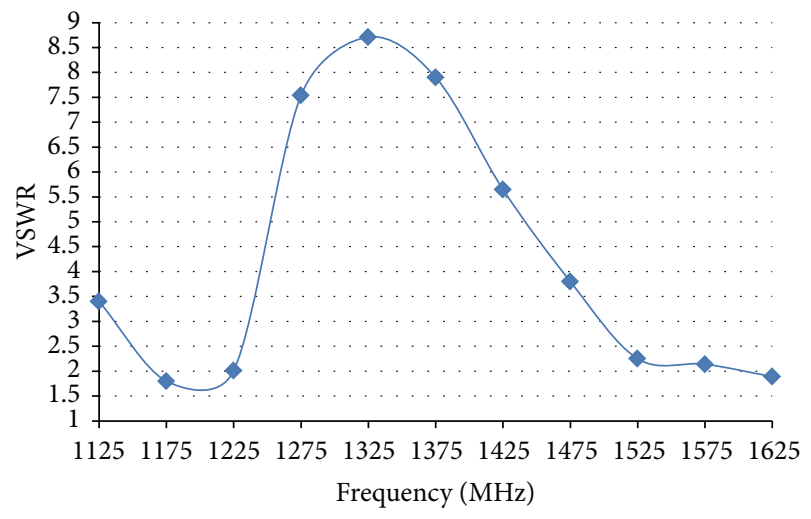

FIGURE 7: VSWR variation for the modified PIFA.

where $u(x)$ is the step function defined as

$$
u(x)= \begin{cases}1, & x \geq 0 \\ 0, & x<0\end{cases}
$$

At the main lobe ends the desired lobe level is $3 \mathrm{~dB}$ below the maximum gain; thus the associated error term is

$$
e_{2}=\frac{1}{2} \sum_{f} \sum_{\phi= \pm 45^{\circ}}\left(\frac{G(\phi) / G_{\max }-0.5}{0.5}\right)^{2}
$$

Outside the main lobe, where there exist 269 points, the relative sidelobe level should not exceed $-6 \mathrm{~dB}$. Therefore, the error term is

$$
e_{3}=\frac{1}{269} \sum_{f} \sum_{\phi=46^{\circ}}^{314^{\circ}}\left[\left(\frac{G(\phi) / G_{\max }-0.25}{0.25}\right)^{2} u\left(\frac{G(\phi)}{G_{\max }}-0.25\right)\right] \text {. }
$$



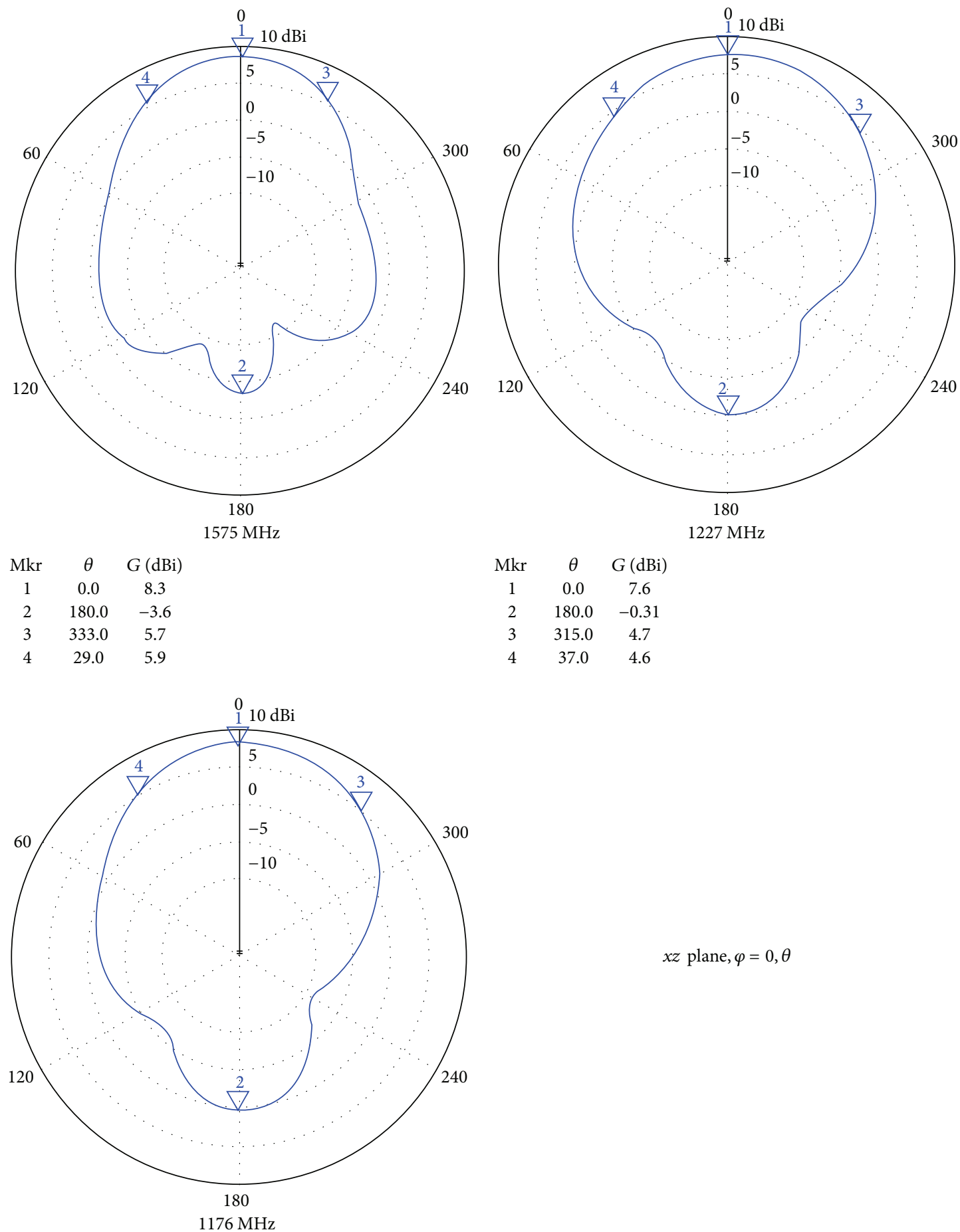

$x z$ plane, $\varphi=0, \theta$

$\begin{array}{ccc}\mathrm{Mkr} & \theta & G(\mathrm{dBi}) \\ 1 & 0.0 & 8.3 \\ 2 & 180.0 & 0.11 \\ 3 & 321.0 & 5.3 \\ 4 & 32.0 & 5.3\end{array}$

FIGURE 8: Radiation patterns at $x z$ plane for the modified PIFA at $1575 \mathrm{MHz}, 1227 \mathrm{MHz}$, and $1176 \mathrm{MHz}$. 
TABLE 3: Input parameters and results of the GA optimization procedure for the 5-element circular switched parasitic element with two active elements.

\begin{tabular}{|c|c|c|c|c|}
\hline Parameter & Range of variation & Step of variation & GA result & Results in physical dimensions \\
\hline Length of central element & $0.05 \lambda_{\mathrm{o}}: 2.05 \lambda_{\mathrm{o}}$ & $0.05 \lambda_{\mathrm{o}}$ & $0.8 \lambda_{\mathrm{o}}$ & $6.31 \mathrm{~cm}$ \\
\hline Length of peripheral elements & $0.05 \lambda_{\mathrm{o}}: 2.05 \lambda_{\mathrm{o}}$ & $0.05 \lambda_{\mathrm{o}}$ & $0.55 \lambda_{\mathrm{o}}$ & $4.34 \mathrm{~cm}$ \\
\hline Distance between central and peripheral elements & $0.05 \lambda_{\mathrm{o}}: 0.5 \lambda_{\mathrm{o}}$ & $0.05 \lambda_{\mathrm{o}}$ & $0.4 \lambda_{\mathrm{o}}$ & $3.16 \mathrm{~cm}$ \\
\hline
\end{tabular}

TABLE 4: Properties of the proposed modified PIFA.

\begin{tabular}{lcccc}
\hline Frequencies & VSWR & Gain $(\mathrm{dBi})$ & Front-to-back ratio $(\mathrm{dB})$ & $3 \mathrm{~dB}$ beamwidth \\
\hline L1 $(1575 \mathrm{MHz})$ & 2.14 & 8.8 & 12.4 & $56^{\circ}$ \\
L2 $(1227 \mathrm{MHz})$ & 1.86 & 7.6 & 7.91 & $82^{\circ}$ \\
L5 $(1176 \mathrm{MHz})$ & 3.41 & 8.3 & 8.19 & $71^{\circ}$ \\
\hline
\end{tabular}

TABLE 5: Properties of the proposed helical antenna above ground plane.

\begin{tabular}{lcccc}
\hline Frequencies & VSWR & Gain $(\mathrm{dBi})$ & Front-to-back ratio $(\mathrm{dB})$ & $3 \mathrm{~dB}$ beamwidth \\
\hline L1 $(1575 \mathrm{MHz})$ & 1.94 & 10 & 25 & $60^{\circ}$ \\
L2 $(1227 \mathrm{MHz})$ & 1.58 & 9.5 & 10.27 & $62^{\circ}$ \\
L5 $(1176 \mathrm{MHz})$ & 1.77 & 9.1 & 8.64 & $64^{\circ}$ \\
\hline
\end{tabular}

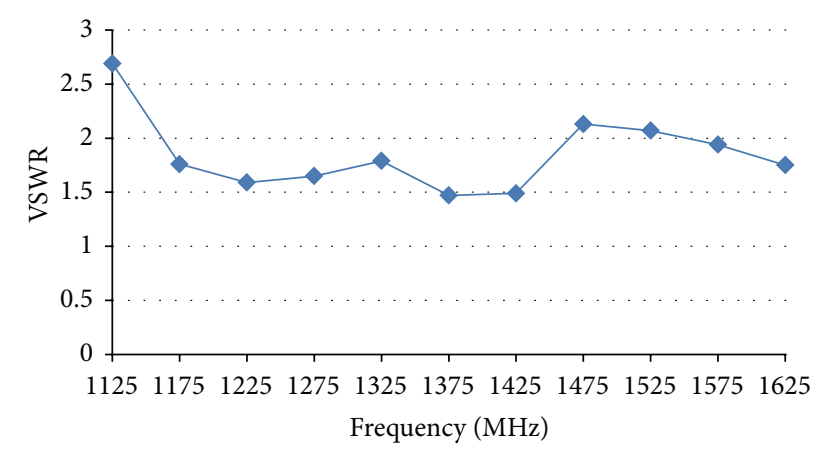

FIGURE 9: VSWR variation for helical antenna above ground plane.

In order to simultaneously attain a driving impedance matching to $50 \Omega$ feeding line at each active element, an additional error term is computed as

$$
e_{4}=\operatorname{abs}\left(\frac{R_{\text {in }}-50}{50}\right)^{2}+\operatorname{abs}\left(\frac{X_{\text {in }}}{50}\right)^{2}
$$

where $R_{\text {in }}$ and $X_{\text {in }}$ correspond to the real and imaginary part of the input impedance, respectively.

Given the fact that the designed procedure aims at the achievement of the desired attributes over a frequency band, the procedure described so far is repeated for a number of discrete frequencies $P$ lying within this band and the total cumulative error is calculated as

$$
\operatorname{err}=\frac{1}{P} \sum_{p=1}^{P} \sum_{i=1}^{4} w_{i} e_{i}\left(f_{p}\right)
$$

where

$$
f_{p}=f_{L}+(p-1) \frac{f_{U}-f_{L}}{P-1}
$$

are uniformly distributed frequency points in the bandwidth interval $\left[f_{L}, f_{U}\right]$ and $e_{i}\left(f_{p}\right)$ is the $i$ th relative error which refers to frequency point $f_{p}$.

After the total error is found, the objective function is estimated as

$$
\mathrm{OF}=\frac{1}{1+\sqrt{\mathrm{err}}}
$$

During the specific design, 5 frequency points are involved in the overall process, uniformly distributed in the interval $[3300 \mathrm{MHz}, 3800 \mathrm{MHz}$, in order to guarantee that the final configuration exhibits broadband attributes with respect to radiation patterns and the input impedance. 

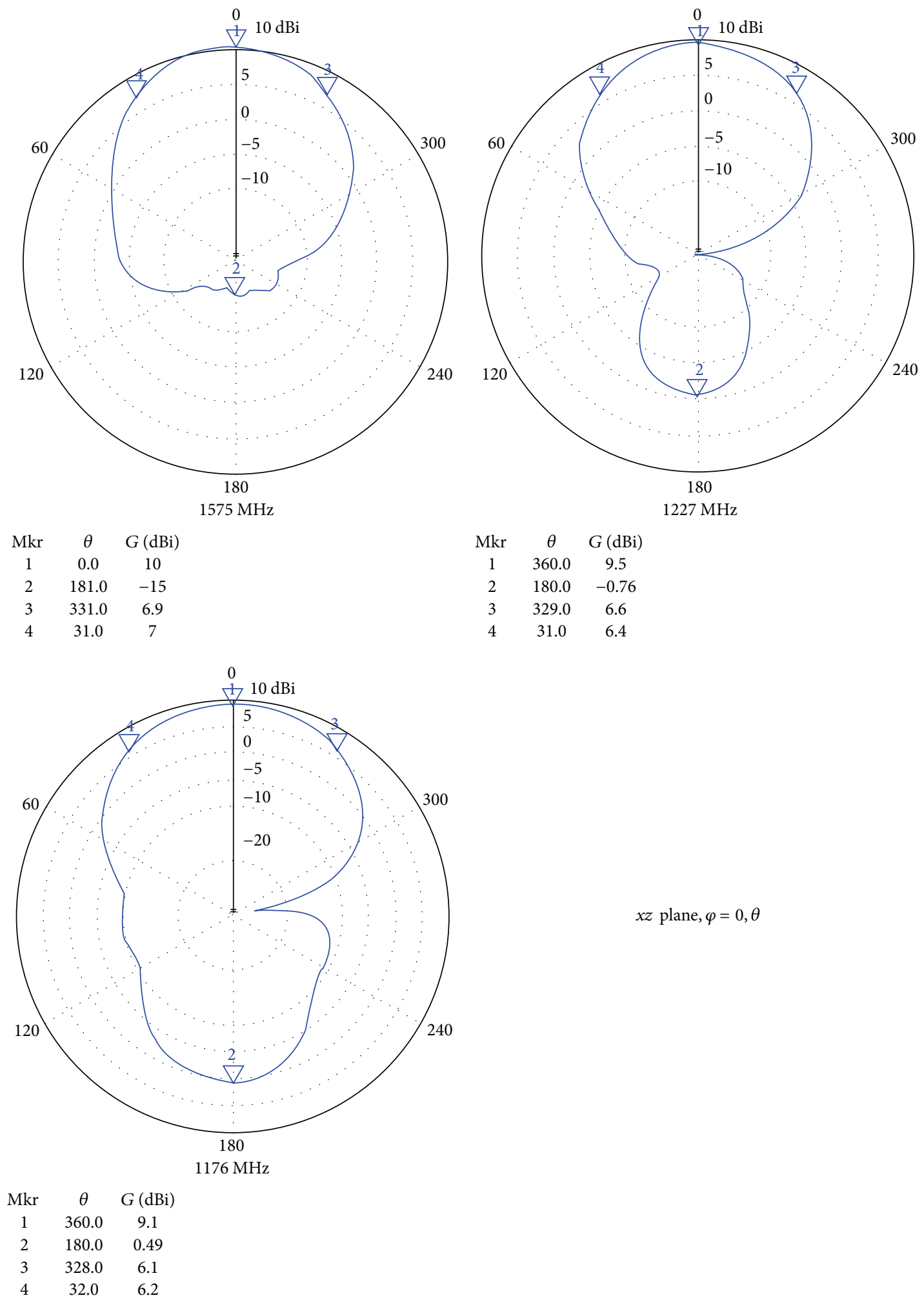

FIGURE 10: Radiation patterns at $x z$ plane for the helical antenna above ground plate at $1575 \mathrm{MHz}, 1227 \mathrm{MHz}$, and $1176 \mathrm{MHz}$. 


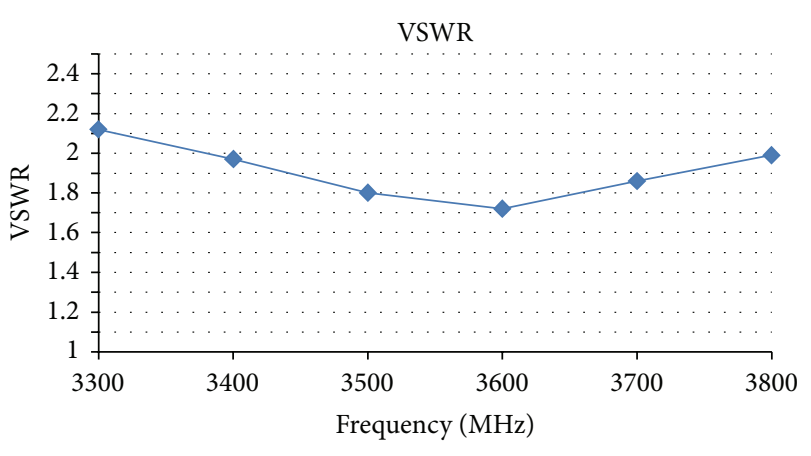

FIGURE 11: VSWR variation for the circular SPA with two active elements.

Let $\lambda_{\mathrm{o}}$ be the wavelength at $3800 \mathrm{MHz}$. In Table 3, the range of each component parameter taking part in the optimization procedure is shown. The wire radius of each element is $0.008 \lambda_{0}$. A total of 250 generations are simulated, with 60 chromosomes per generation. The selection method is population decimation, while adjacent fitness pairing is the mating scheme. The crossover point is chosen randomly and each chromosome is divided at a gene level. The mutation probability is equal to 0.15 .

\section{Results}

3.1. Numerical Results of the Modified PIFA. In Table 4 the properties of the resulting configuration are summarized.

The VSWR variation of the modified PIFA is plotted in Figure 7.

The far field patterns of the PIFA are plotted in Figure 8. As it can be drawn out from this figure, the highest gain is computed at the $\left(\varphi=0^{\circ}, \theta=0^{\circ}\right)$ directions. Its value is totally appropriate for the GNSS applications, where this antenna is intended to operate.

\subsection{Numerical Results of the Helical Antenna above Ground} Plane. The dimensions of the resulting structure are approximately $10 \mathrm{~cm} \times 10 \mathrm{~cm} \times 10 \mathrm{~cm}$, as it can be extracted from Table 2. In Table 5 its attributes are summarized.

A remarkable characteristic concerns the low values of VSWR, which are always below 2 .

The VSWR variation for the helical antenna is plotted in Figure 9.

The far field patterns of the helical antenna are plotted in Figure 10. As it can be drawn out from this figure, the highest gain is computed at the $\left(\varphi=0^{\circ}, \theta=0^{\circ}\right)$ directions. Its value is totally appropriate for the GNSS applications, where this antenna is intended to operate.

3.3. Numerical Results of the Circular Switched Parasitic Array. The final results of the algorithm are included in Table 3. In Figure 11, the variation of VSWR at each feed point within
TABLE 6: Properties of radiation patterns of the CSPA.

\begin{tabular}{lccc}
\hline Frequencies & Gain $(\mathrm{dBi})$ & $\begin{array}{c}\text { Front-to-back ratio } \\
(\mathrm{dB})\end{array}$ & $3 \mathrm{~dB}$ beamwidth \\
\hline $3300 \mathrm{MHz}$ & 6.3 & 7.11 & $90^{\circ}$ \\
$3500 \mathrm{MHz}$ & 5.2 & 8.3 & $100^{\circ}$ \\
$3800 \mathrm{MHz}$ & 4.5 & 6.8 & $96^{\circ}$ \\
\hline
\end{tabular}

the frequency band of [ $3300 \mathrm{MHz}-3800 \mathrm{MHz}$ is plotted. It is important that VSWR is kept below 2 for the entire frequency zone of interest.

The azimuth far field radiation patterns for this structure at $3300 \mathrm{MHz}, 3500 \mathrm{MHz}$, and $3800 \mathrm{MHZ}$ are also presented in Figure 12. The shape of the radiation pattern generally satisfies the specifications within the frequency range of $3300 \mathrm{MHz}-$ $3800 \mathrm{MHz}$. More details are provided in Table 6.

The main advantages of employing this specific antenna system include the following.

(i) In a fading environment the user has the possibility to select among the four predefined beams the one that provides highest signal level.

(ii) As it can be extracted from Table 6, the array exhibits significant front gain (4.5-6.3 dBi), outperforming conventional dipoles already used for WiMax applications. This can be proved very effective in cases where the Wimax service providers are not allowed to increase their radiated power to improve their coverage.

(iii) Its overall size is considered rather compact and therefore easy to be installed.

\section{Conclusions}

This paper aims to present the new challenges and the progress in the field of GAs methods in antenna engineering. Firstly, the application of GA to several antenna design and optimization problems covering diverse areas of interest is cited. Subsequently, in order to demonstrate how a GA is employed in antenna design, three antenna systems are developed, proposed for modern commercial applications: a modified PIFA and a helical antenna for GNSS solutions and a SPA for WiMAx solutions. In all of these cases, where the optimal design of an antenna structure is searched out, each member of the population in the GA is an antenna representing a possible solution and therefore its electromagnetic properties are analyzed. By applying the mechanisms of GA, the final configuration is derived, which satisfies the most of the design requirements. 

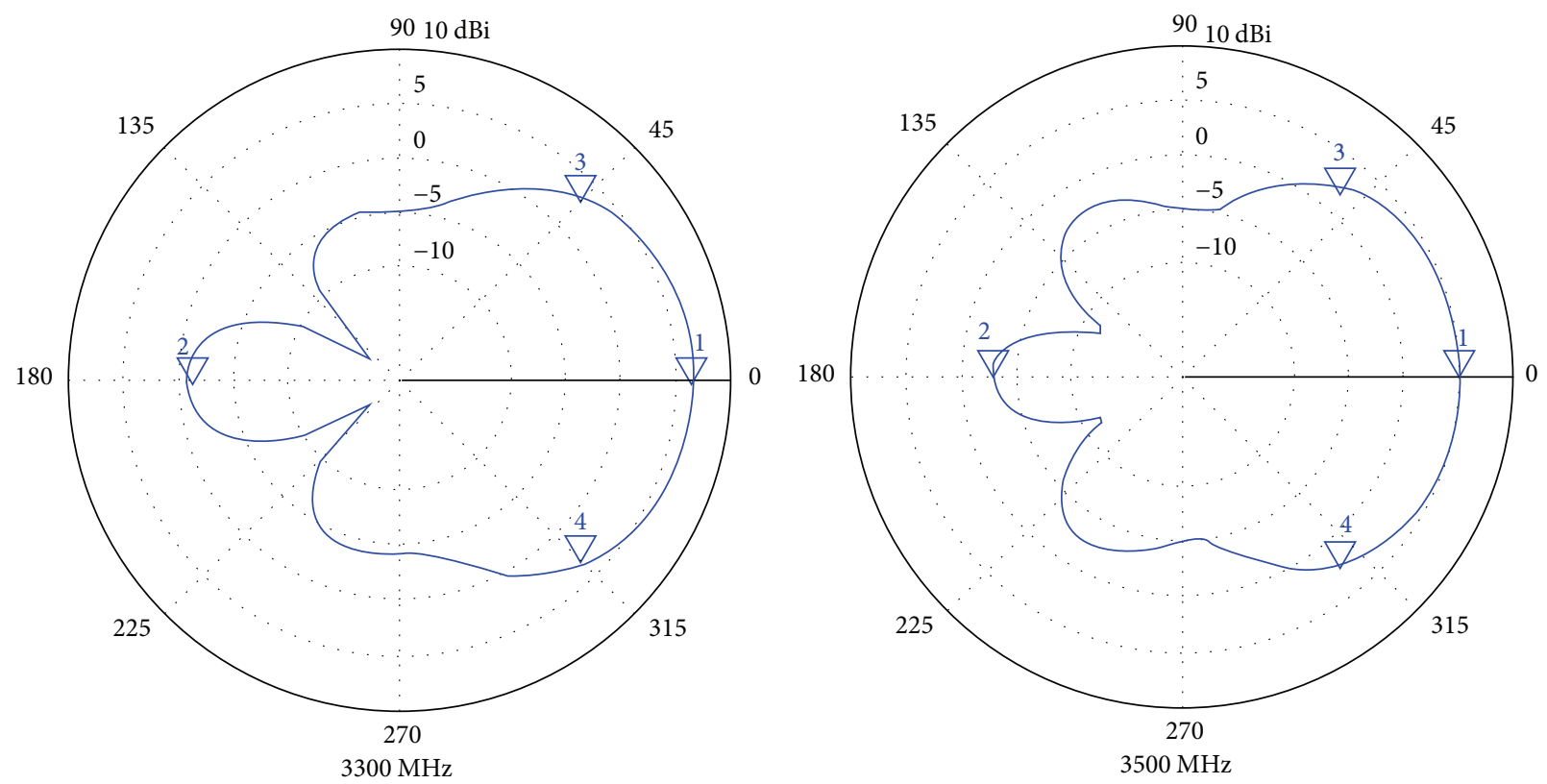

$$
\begin{array}{ccc}
\mathrm{Mkr} & \phi & G(\mathrm{dBi}) \\
1 & 0.0 & 5.3 \\
2 & 180.0 & -0.81 \\
3 & 45.0 & 3.3 \\
4 & 315.0 & 3.3
\end{array}
$$

$\begin{array}{ccc}\mathrm{Mkr} & \phi & G(\mathrm{dBi}) \\ 1 & 0.0 & 5.2 \\ 2 & 180.0 & -3.1 \\ 3 & 50.0 & 2.2 \\ 4 & 310.0 & 2.2\end{array}$

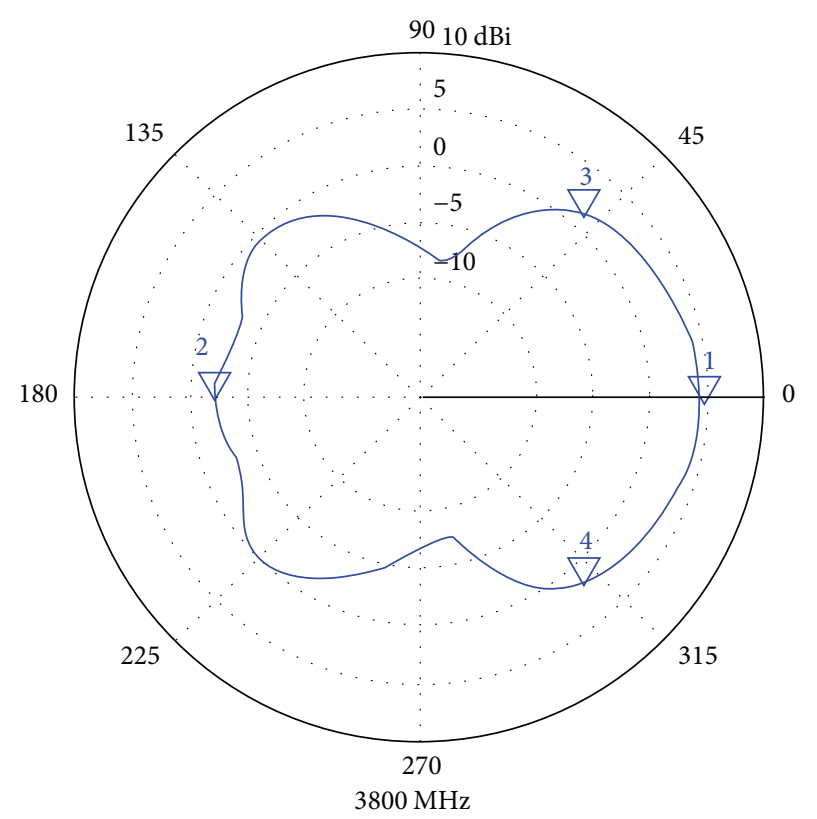

$x y$ plane, $\theta=90, \varphi$

$$
\begin{array}{ccc}
\mathrm{Mkr} & \phi & G(\mathrm{dBi}) \\
1 & 0.0 & 4.5 \\
2 & 180.0 & -2.3 \\
3 & 48.0 & 1.5 \\
4 & 312.0 & 1.5
\end{array}
$$

Figure 12: Radiation patterns at $x y$ plane for the CSPA at $3300 \mathrm{MHz}, 3500 \mathrm{MHz}$, and $3800 \mathrm{MHz}$. 


\section{Conflict of Interests}

The authors declare that there is no conflict of interests regarding the publication of this paper.

\section{Acknowledgment}

This work is supported by the "HIPOW" EU research project ("Protection of Critical Infrastructures against High Power Microwave Threats" HIPOW-FP7-SEC-2011-284802).

\section{References}

[1] J. H. Holland, Adaptation in Natural and Artificial Systems, MIT Press, 1975.

[2] K. A. de Jong, An analysis of the behavior of a class of genetic adaptive systems [Ph.D. thesis], University of Michigan Press, Ann Arbor, Mich, USA, 1975.

[3] D. E. Goldberg, Genetic Algorithms in Search, Optimization and Machine Learning, Addison-Wesley, Reading, Mass, USA, 1989.

[4] R. L. Haupt, "An introduction to genetic algorithms for electromagnetics," IEEE Antennas and Propagation Magazine, vol. 37, no. 2, pp. 7-15, 1995.

[5] J. M. Johnson and Y. Rahmat-Samii, "Genetic algorithms in engineering electromagnetics," IEEE Antennas and Propagation Magazine, vol. 39, no. 4, pp. 7-21, 1997.

[6] J. M. Johnson and Y. Rahmat-samii, "Genetic algorithm optimization and its application to antenna design," in Proceedings of the IEEE Antennas and Propagation International Symposium, pp. 326-329, June 1994.

[7] B. Orchard, Optimising algorithms for antenna design [M.S. dissertation], University of the Witwatersrand, 2002.

[8] R. L. Haupt and D. H. Werner, Genetic Algorithms in Electromagnetics, John Wiley \& Sons, Upper Saddle River, NJ, USA, 2007.

[9] A. Oyama, S. Obayashi, and T. Nakamura, "Real-coded adaptive range genetic algorithm applied to transonic wing optimization," Applied Soft Computing, vol. 1, no. 3, pp. 179-187, 2001.

[10] D. F. Jones, S. K. Mirrazavi, and M. Tamiz, "Multi-objective meta-heuristics: an overview of the current state-of-the-art," European Journal of Operational Research, vol. 137, no. 1, pp. 1-9, 2002.

[11] R. Saha, P. Chaudhury, and S. P. Bhattacharyya, "Direct solution of Schrödinger equation by genetic algorithm: test cases," Physics Letters A, vol. 291, no. 6, pp. 397-406, 2001.

[12] H. T. Chou, Y. C. Hou, and W. J. Liao, "A dual band patch antenna design for WLAN and DSRC applications based on a genetic algorithm optimization," Electromagnetics, vol. 27, no. 5, pp. 253-262, 2007.

[13] D. A. Tonn and R. Bansal, "Reduction of sidelobe levels in interrupted phased array antennas by means of a genetic algorithm," International Journal of RF and Microwave ComputerAided Engineering, vol. 17, no. 2, pp. 134-141, 2007.

[14] M. A. Panduro, "Design of coherently radiating structures in a linear array geometry using genetic algorithms," AEU: International Journal of Electronics and Communications, vol. 61, no. 8, pp. 515-520, 2007.
[15] M. E. Aydemir, T. Günel, and F. Üstüner, "Genetic approach to the minimization of the coupling between aircraft antennas," AEU-International Journal of Electronics and Communications, vol. 60, no. 4, pp. 299-305, 2006.

[16] M. A. Panduro, A. L. Mendez, R. Dominguez, and G. Romero, "Design of non-uniform circular antenna arrays for side lobe reduction using the method of genetic algorithms," $A E U$ International Journal of Electronics and Communications, vol. 60, no. 10, pp. 713-717, 2006.

[17] C. H. Chan, S. H. Yeung, W. S. Chan, and K. F. Man, "Genetic algorithm optimized printed UWB sickle-shape dipolar antenna with stable radiation pattern," Microwave and Optical Technology Letters, vol. 49, no. 11, pp. 2695-2697, 2007.

[18] A. Recioui and A. Azrar, "Use of genetic algorithms in linear and planar antenna array synthesis based on Schelkunoff method," Microwave and Optical Technology Letters, vol. 49, no. 7, pp. 1619-1623, 2007.

[19] S. Baskar, A. Alphones, and P. N. Suganthan, "Genetic-algorithm-based design of a reconfigurable antenna array with discrete phase shifters," Microwave and Optical Technology Letters, vol. 45, no. 6, pp. 461-465, 2005.

[20] F. Bilotti, F. Castellana, and L. Vegni, "Multi-frequency patch antenna design via the method of moment and genetic algorithm," Microwave and Optical Technology Letters, vol. 35, no. 3, pp. 184-186, 2002.

[21] J. R. Pérez and J. Basterrechea, "Antenna far-field pattern reconstruction using equivalent currents and genetic algorithms," Microwave and Optical Technology Letters, vol. 42, no. 1, pp. 21$25,2004$.

[22] S. M. Meriah, E. Cambiaggio, F. T. Bendimerad, R. Staraj, J. P. Damiano, and L. Brochier, "Design of a thinned microstripantenna reflectarray using a genetic algorithm," Microwave and Optical Technology Letters, vol. 46, no. 6, pp. 559-562, 2005.

[23] S. S. Pattnaik, B. Khuntia, D. C. Panda, D. K. Neog, and S. Davi, "Calculation of optimized parameters of rectangular microstrip patch antenna using genetic algorithm," Microwave and Optical Technology Letters, vol. 37, no. 6, pp. 431-433, 2003.

[24] X. Chen, K. Huang, and X.-B. Xu, "Automated design of a threedimensional fishbone antenna using parallel genetic algorithm and NEC," IEEE Antennas and Wireless Propagation Letters, vol. 4, no. 1, pp. 425-428, 2005.

[25] D. Arnaud-Cormos, R. Loison, and R. Gillard, "Fast multistructure method of moments combined with a genetic algorithm (MSMOM/GA) for efficient optimization of printed antennas," IEEE Antennas and Wireless Propagation Letters, vol. 6, pp. 172$174,2007$.

[26] T. Xiang, K. F. Man, K. M. Luk, and C. H. Chan, "Design of multiband miniature handset antenna by MoM and HGA," IEEE Antennas and Wireless Propagation Letters, vol. 5, no. 1, pp. 179-182, 2006.

[27] E. E. Altshuler and D. S. Linden, "An ultrawide-band impedance-loaded genetic antenna," IEEE Transactions on Antennas and Propagation, vol. 52, no. 11, pp. 3147-3150, 2004.

[28] R. L. Haupt, "Calibration of cylindrical reflector antennas with linear phased array feeds," IEEE Transactions on Antennas and Propagation, vol. 56, no. 2, pp. 593-596, 2008.

[29] C. I. Tsitouri, S. C. Panagiotou, T. D. Dimousios, and C. N. Capsalis, "A circular switched parasitic array of log-periodic antennas with enhanced directivity and beam steering capability for ultra wideband communications applications," in Proceedings of the Loughborough Antennas and Propagation Conference (LAPC '08), pp. 281-284, Loughborough, UK, March 2008. 
[30] G. G. Chavka and N. Litwinczuk, "Design of wire antennas with using of genetic algorithms," in Proceedings of the 6th International Conference on Antenna Theory and Techniques (ICATT '07), pp. 220-222, September 2007.

[31] H. Hu, W. Qin, and S. Feng, "Optimizing the architecture of planar phased array by improved genetic algorithm," in Proceedings of the IEEE International Symposium on Microwave, Antenna, Propagation, and EMC Technologies for Wireless Communications (MAPE '07), pp. 676-679, August 2007.

[32] A. Rolland, R. Sauleau, and M. Drissi, "Full wave synthesis of integrated lens antennas using FDTD and genetic algorithms," in Proceedings of the 2nd European Conference on Antennas and Propagation (EuCAP '07), Edinburgh, UK, November 2007.

[33] K. Michael and A. A. Kucharski, "GA/MoM optimization of PIFA antennas with meandering slits," in Proceedinsg of the 2nd European Conference on Antennas and Propagation (EuCAP '07), Edinburgh, UK, November 2007.

[34] Y. Ravinder and V. M. Pandharipande, "Genetic algorithm assisted dual diversity smart antenna with Triple-COLD array for QPSK communication system," in Proceedings of the International Conference on Electromagnetics in Advanced Applications (ICEAA '07), pp. 723-726, Torino, Italy, September 2007.

[35] J. Chung, R. Abd-Alhameed, and P. Excell, "Design of wire bowtie antenna for near field imaging using genetic algorithms," in Proceedings of the Loughborough Antennas and Propagation Conference (LAPC '08), pp. 317-320, Loughborough, UK, March 2008.

[36] Z. Altman, R. Mittra, and A. Boag, "New designs of ultra wideband communication antennas using a genetic algorithm," IEEE Transactions on Antennas and Propagation, vol. 45, no. 10, pp. 1494-1501, 1997.

[37] P. L. Werner, Z. Altman, R. Mittra, D. H. Werner, and A. J. Ferraro, "Optimization of stacked vertical dipoles above a ground plane using the genetic algorithm," Journal of Electromagnetic Waves and Applications, vol. 13, no. 1, pp. 51-66, 1999.

[38] E. A. Jones and W. T. Joines, "Genetic design of linear antenna arrays," IEEE Antennas and Propagation Magazine, vol. 42, no. 3, pp. 92-100, 2000.

[39] D. Marcano and F. Durán, "Synthesis of antenna arrays using genetic algorithms," IEEE Antennas and Propagation Magazine, vol. 42, no. 3, pp. 12-20, 2000.

[40] S. D. Rogers, C. M. Butler, and A. Q. Martin, "Realization of a genetic-algorithm-optimized wire antenna with 5:1 bandwidth," Radio Science, vol. 36, no. 6, pp. 1315-1325, 2001.

[41] S. L. Avila, J. Carpes, and J. A. Vasconcelos, "Optimization of an offset reflector antenna using genetic algorithms," IEEE Transactions on Magnetics, vol. 40, no. 2, pp. 1256-1259, 2004.

[42] Y. C. Ji, Q. Z. Liu, X. L. He, and H. Zhang, "Optimal designs of ultra wide-band communication antennas," Chinese Journal of Electronics, vol. 13, no. 4, pp. 728-731, 2004.

[43] M. Donelli, S. Caorsi, F. de Natale, D. Franceschini, and A. Massa, "A versatile enhanced genetic algorithm for planar array design," Journal of Electromagnetic Waves and Applications, vol. 18, no. 11, pp. 1533-1548, 2004.

[44] P. K. Varlamos and C. N. Capsalis, "Electronic beam steering using switched parasitic smart antenna arrays," Progress in Electromagnetics Research, vol. 36, pp. 101-119, 2002.

[45] P. K. Varlamos and C. N. Capsalis, "Design of a six-sector switched parasitic planar array using the method of genetic algorithms," Wireless Personal Communications, vol. 26, no. 1, pp. 77-88, 2003.
[46] J. Jayasinghe, J. Anguera, and D. Uduwawala, "Genetic algorithm optimization of a high-directivity microstrip patch antenna having a rectangular profile," Radioengineering, vol. 22, no. 3, pp. 700-707, 2013.

[47] J. W. Jayasinghe and D. N. Uduwawala, "A novel miniature multi-frequency broadband patch antenna for WLAN applications," in Proceedings of the IEEE 8th International Conference on Industrial and Information Systems (ICIIS '13), pp. 361-363, Peradeniya, Sri Lanka, December 2013.

[48] M. H. Öktem and B. Saka, "Design of multilayered cylindrical shields using a genetic algorithm," IEEE Transactions on Electromagnetic Compatibility, vol. 43, no. 2, pp. 170-176, 2001.

[49] L. Dawson, J. Clegg, S. J. Porter, J. F. Dawson, and M. J. Alexander, "The use of genetic algorithms to maximize the performance of a partially lined screened room," IEEE Transactions on Electromagnetic Compatibility, vol. 44, no. 1, pp. 233-242, 2002.

[50] Y. Rahmat-Samii and E. Michielssen, Electromagnetic Optimization by Genetic Algorithms, John Wiley and Sons, New York, NY, USA, 1999.

[51] D. S. Weile and E. Michielssen, "genetic algorithm optimization applied to electromagnetics: a review," IEEE Transactions on Antennas and Propagation, vol. 45, no. 3, pp. 343-353, 1997.

[52] J. M. Johnson and Y. Rahmat-Samii, "Genetic algorithms and method of moments (GA/MOM) for the design of integrated antennas," IEEE Transactions on Antennas and Propagation, vol. 47, no. 10, pp. 1606-1614, 1999.

[53] T. Su, "Determining the equivalent impedance boundary condition for corrugated coatings based on the genetic algorithm," IEEE Transactions on Antennas and Propagation, vol. 48, no. 3, pp. 374-382, 2000.

[54] Z. F. Li, Y. E. Erdemli, J. L. Volakis, and P. Y. Papalambros, "Design optimization of conformal antennas by integrating stochastic algorithms with the hybrid finite-element method," IEEE Transactions on Antennas and Propagation, vol. 50, no. 5, pp. 676-684, 2002.

[55] M. J. Varnamkhasti and L. S. Lee, "A fuzzy genetic algorithm based on binary encoding for solving multidimensional knapsack problems," Journal of Applied Mathematics, vol. 2012, Article ID 703601, 23 pages, 2012.

[56] M. J. Varnamkhasti, L. S. Lee, M. R. Abu Bakar, and W. J. Leong, "A genetic algorithm with fuzzy crossover operator and probability," Advances in Operations Research, Article ID 956498, 16 pages, 2012.

[57] W. Chien and C.-C. Chiu, "Using NU-SSGA to reduce the searching time in inverse problem of a buried metallic object," IEEE Transactions on Antennas and Propagation, vol. 53, no. 10, pp. 3128-3134, 2005.

[58] S. Cui, A. Mohan, and D. S. Weile, "Pareto optimal design of absorbers using a parallel elitist nondominated sorting genetic algorithm and the finite element-boundary integral method," IEEE Transactions on Antennas and Propagation, vol. 53, no. 6, pp. 2099-2107, 2005.

[59] P. K. Varlamos, P. J. Papakanellos, S. C. Panagiotou, and C. N. Capsalis, "Multi-objective genetic optimization of Yagi-Uda arrays with additional parasitic elements," IEEE Antennas and Propagation Magazine, vol. 47, no. 4, pp. 92-97, 2005.

[60] D. W. Boeringer, D. H. Werner, and D. W. Machuga, "A simultaneous parameter adaptation scheme for genetic algorithms with application to phased array synthesis," IEEE Transactions on Antennas and Propagation, vol. 53, no. 1, pp. 356-371, 2005. 
[61] S. C. Panagiotou, S. A. Mitilineos, T. D. Dimousios, and C. N. Capsalis, "A broadband, vertically polarized, circular switched parasitic array for indoor portable DVB-T applications at the IV UHF band," IEEE Transactions on Broadcasting, vol. 53, no. 2, pp. 547-552, 2007.

[62] S. C. Panagiotou, S. A. Mitilineos, T. D. Dimousios, and C. N. Capsalis, "A broadband, circular switched parasitic array for portable and vehicular mobile DVB-T applications at the V UHF band," Microwave and Optical Technology Letters, vol. 50, no. 7, pp. 1727-1732, 2008.

[63] S. C. Panagiotou, T. D. Dimousios, S. A. Mitilineos, and C. N. Capsalis, "Broadband switched parasitic arrays for portable DVB-T receiver applications in the VHF/UHF bands," IEEE Antennas and Propagation Magazine, vol. 50, no. 5, pp. 110-117, 2008.

[64] V. G. Tsiafakis, A. I. Sotiriou, Y. I. Petropoulos, E. S. Psarropoulos, E. D. Nanou, and C. N. Capsalis, "Design of a wideband espar antenna for DVB-T reception," Progress in Electromagnetics Research B, vol. 12, pp. 183-199, 2009.

[65] S. C. Panagiotou, S. C. A. Thomopoulos, P. J. Papakanellos, and C. N. Capsalis, "A new, compact, low-cost switched-beam array for fixed and portable applications in the V UHF band," in Proceedings of the Loughborough Antennas and Propagation Conference (LAPC '12), November 2012.

[66] SuperNec, v. 2.4, MOM Technical Reference Manual, Poynting Software (Pty) Ltd, http://www.supernec.com/manuals/ snmomtrm.htm.

[67] SuperNec v. 2.4, Genetic Algorithm Optimiser Manual, Poynting Software (Pty).

[68] S. C. Panagiotou, T. D. Dimousios, and C. N. Capsalis, "Analysis and design of a broadband circular switched parasitic array above finite plate and finite plate with skirt," in Proceedings of the International Conference on Electromagnetics in Advanced Applications (ICEAA '07), pp. 727-730, Torino, Italy, September 2007. 

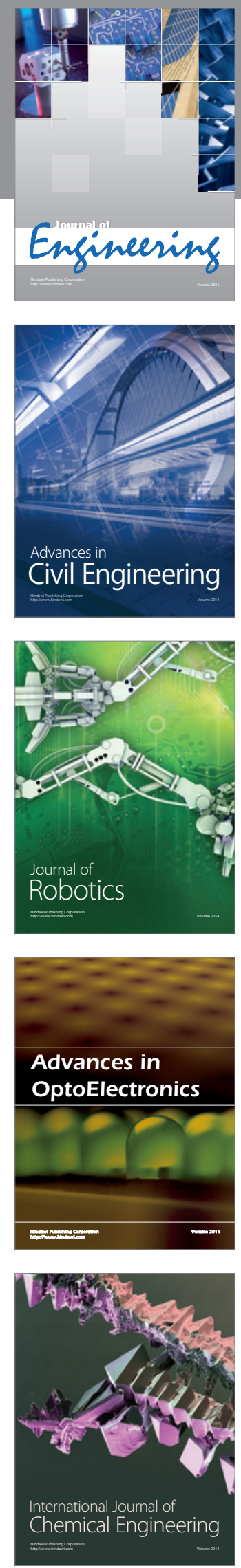

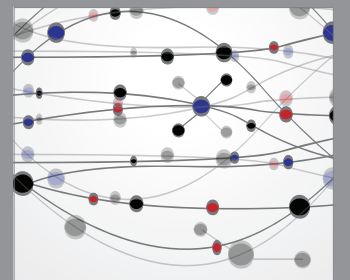

The Scientific World Journal
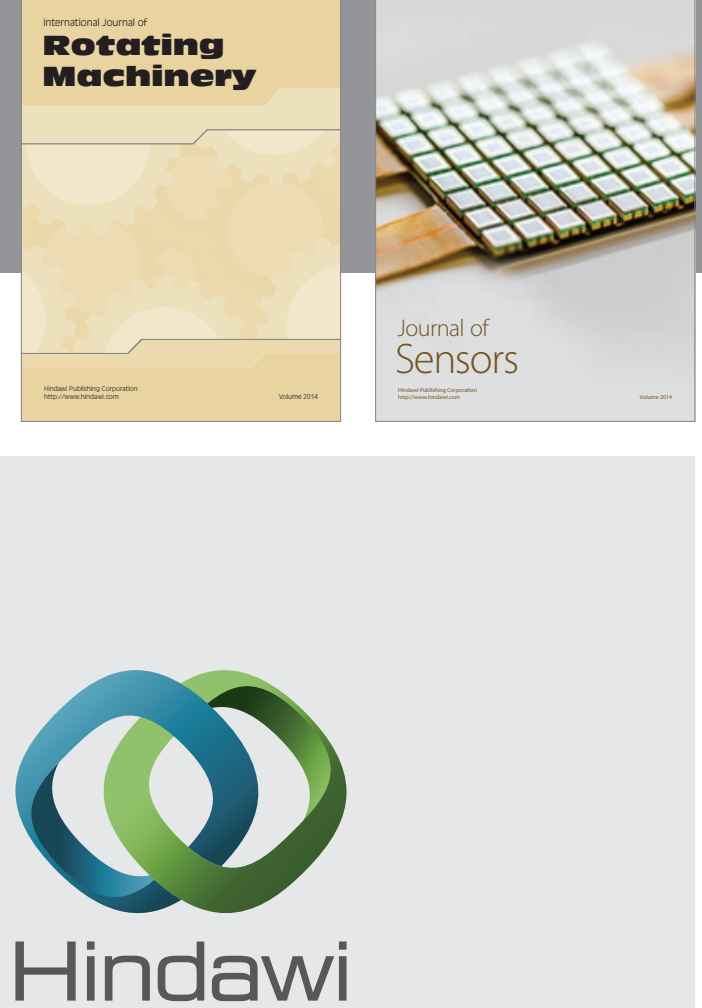

Submit your manuscripts at http://www.hindawi.com
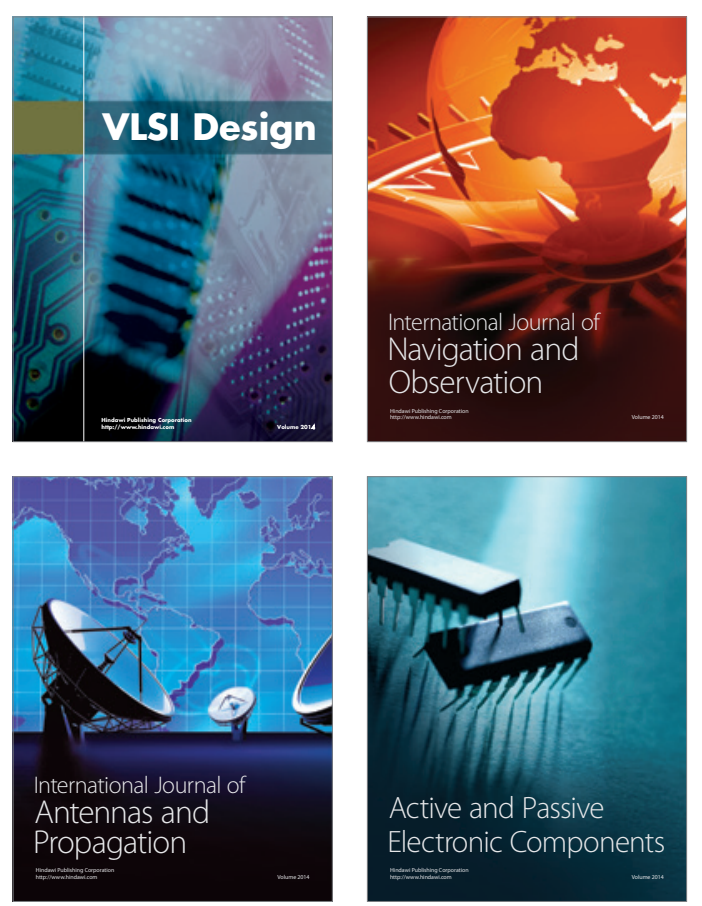
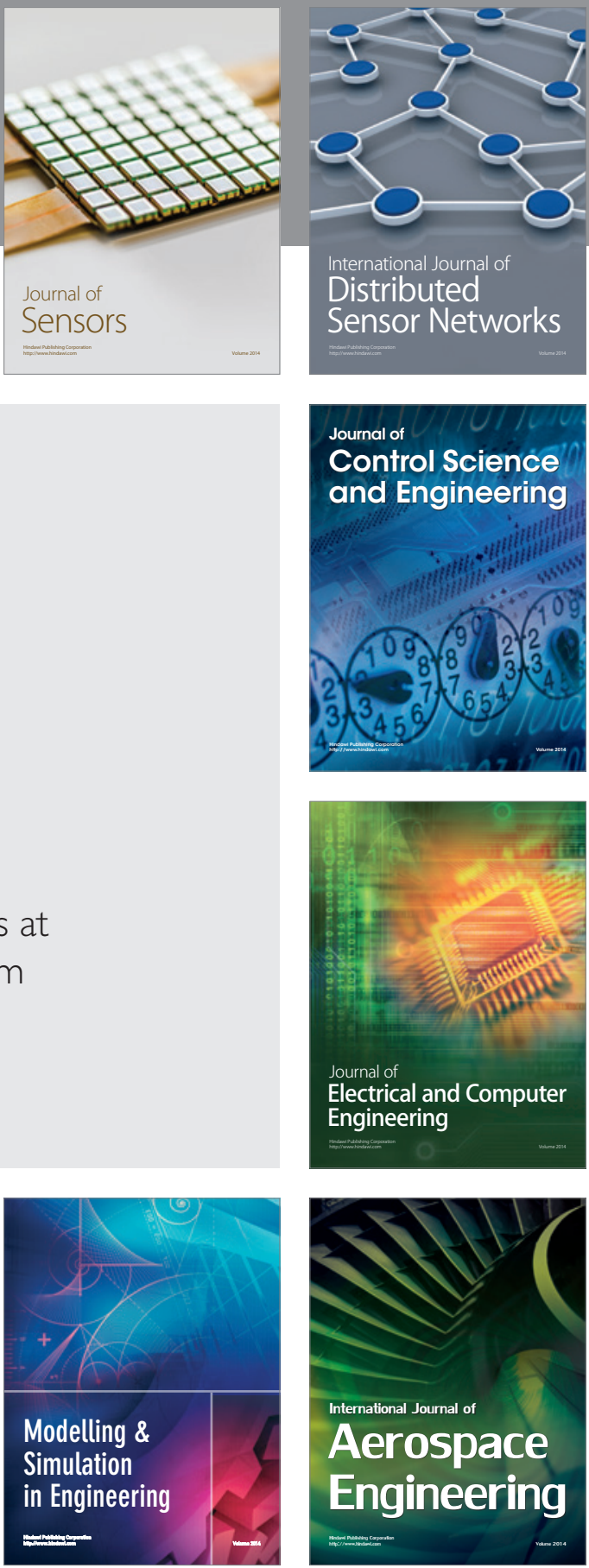

Journal of

Control Science

and Engineering
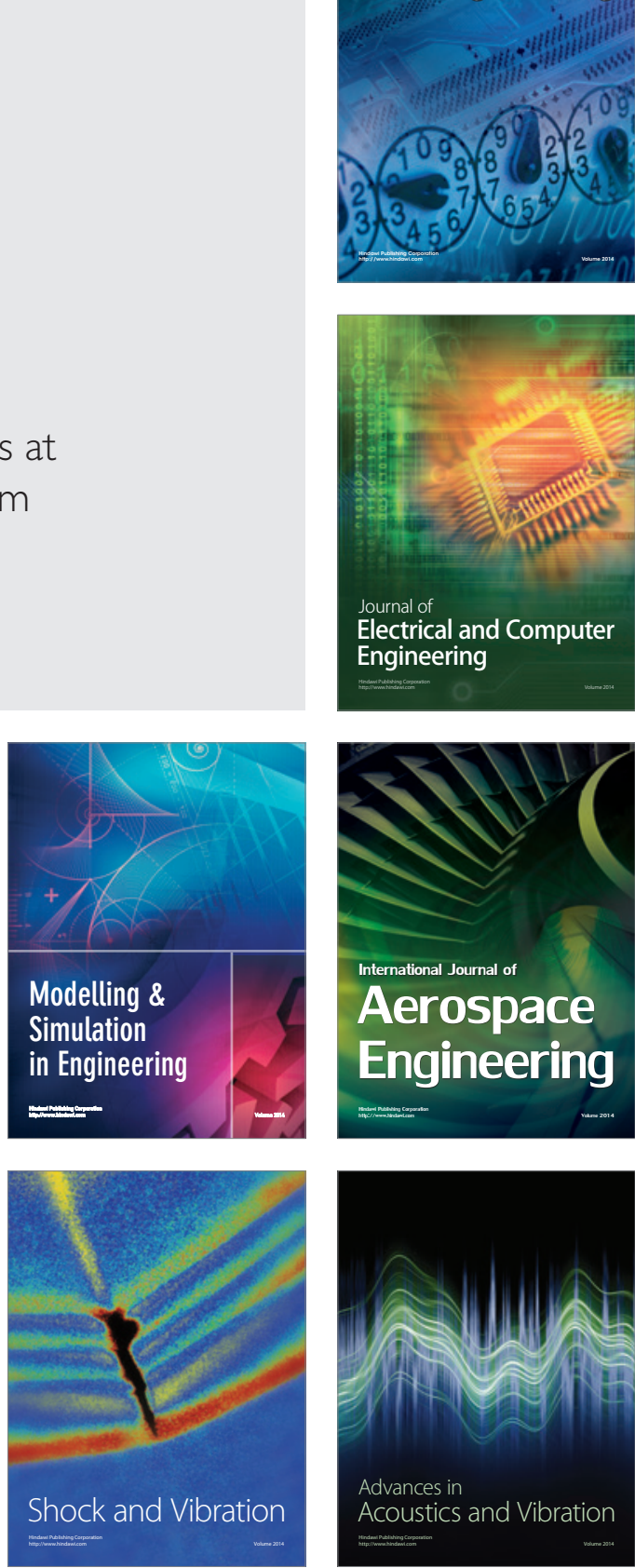